\title{
Bioavailability and mobility of arsenic, cadmium, and manganese in gold mine tailings amended with rice husk ash and Fe-coated rice husk ash
}

\begin{abstract}
This study was conducted to determine the effects of rice husk ash (RHA) and Fe-coated rice husk ash (Fe-RHA) on the bioavailability and mobility of $\mathrm{As}, \mathrm{Cd}$, and $\mathrm{Mn}$ in mine tailings. The amendments were added to the tailings at $0,5,10$, or $20 \%(\mathrm{w} / \mathrm{w})$ and the mixtures were incubated for $0,7,15,30,45$, and 60 days. The $\mathrm{CaCl} 2$ extractable As, $\mathrm{Cd}$, and $\mathrm{Mn}$ in the amended tailings were determined at each interval of incubation period. In addition, the tailings mixture was leached with simulated rain water (SRW) every week from 0 day (D 0) until day 60 (D 60). The results showed that both RHA and Fe-RHA application significantly decreased the $\mathrm{CaCl} 2$-extractable $\mathrm{Cd}$ and $\mathrm{Mn}$ but increased that of $\mathrm{As}$ in the tailings throughout the incubation period. Consequently, addition of both RHA and Fe-RHA leached out higher amount of As from the tailings but decreased $\mathrm{Cd}$ and $\mathrm{Mn}$ concentration compared to the controls. The amount of As leached from the Fe-RHA-amended tailings was less than that from RHA-amended tailings. Application of both RHA and Fe-RHA could be an effective way in decreasing the availability of cationic heavy metals ( $\mathrm{Cd}$ and $\mathrm{Mn}$ ) in the tailings but these amendments could result in increasing the availability of anionic metalloid (As). Therefore, selection of organic amendments to remediate metal contaminated tailings must be done with great care because the outcomes might be different among the elements.
\end{abstract}

Keyword: Availability; Amendments; CaCl2- extractable; Tailings; Incubation; RHA; FeRHA 